\title{
The use of specialised preterm birth clinics for women at high risk of spontaneous preterm birth: a systematic review
}

\author{
Lisa Dawes ${ }^{1,2^{*}}$ (D), Katie Groom ${ }^{1,2}$, Vanessa Jordan ${ }^{3,4}$ and Jason Waugh ${ }^{2,3}$
}

\begin{abstract}
Background: Specialised preterm birth clinics care for women at high risk of spontaneous preterm birth. This systematic review assesses current practice within preterm birth clinics globally.

Methods: A comprehensive search strategy was used to identify all studies on preterm birth clinics on the MEDLINE, Embase, PsycINFO, CENTRAL and CINAHL databases. There were no restrictions to study design. Studies were limited to the English language and publications from 1998 onwards. Two reviewers assessed studies for inclusion, performed data extraction and reviewed methodological quality. Primary outcomes were referral criteria, investigations and interventions offered in preterm birth clinics. Secondary outcomes were the timing of planned first and last appointments and frequency of review.

Results: Thirty-two records fulfilled eligibility criteria and 20 studies were included in the main analysis following grouping of records describing the same study or clinic. Studies were of mixed study design and methodological quality. A total of 39 clinics were described; outcome data was not available for all clinics. Referral criteria included previous spontaneous preterm birth (38/38, 100\%), previous mid-trimester loss $(34 / 38,89 \%)$ and previous cervical surgery $(33 / 38,87 \%)$. All clinics offered transvaginal cervical length scans. Additional investigations varied, including urogenital swabs $(16 / 28,57 \%)$ and fetal fibronectin $(8 / 28,29 \%)$. The primary treatment of choice for a sonographic short cervix was cervical cerclage in 10/33 (30\%) clinics and vaginal progesterone in 6/33 (18\%), with 10/33 (30\%) using multiple first-line options and 6/33 (18\%) using a combination of treatments. The majority of clinics planned timing of first review for 12-16 weeks $(30 / 35,86 \%)$ and the frequency of review was usually determined by clinical findings (18/24, 75\%). There was a wide variation in gestational age at clinic discharge between 24 and 37 weeks.
\end{abstract}

Conclusions: There is variation in the referral criteria, investigations and interventions offered in preterm birth clinics and in the timing and frequency of review. Consistency in practice may improve with the introduction of consensus guidelines and national preterm birth prevention programmes.

Trial registration: Systematic review registration number: CRD42019131470.

Keywords: Specialised preterm birth clinic, Preterm birth prevention clinic, Spontaneous preterm birth

\footnotetext{
*Correspondence: I.dawes@auckland.ac.nz

'Liggins Institute, The University of Auckland, Private Bag 92019, Victoria

Street West, Auckland 1142, New Zealand

${ }^{2}$ National Women's Health, Auckland City Hospital, Auckland, New Zealand

Full list of author information is available at the end of the article
}

C The Author(s). 2020 Open Access This article is distributed under the terms of the Creative Commons Attribution 4.0 International License (http://creativecommons.org/licenses/by/4.0/), which permits unrestricted use, distribution, and reproduction in any medium, provided you give appropriate credit to the original author(s) and the source, provide a link to the Creative Commons license, and indicate if changes were made. The Creative Commons Public Domain Dedication waiver (http://creativecommons.org/publicdomain/zero/1.0/) applies to the data made available in this article, unless otherwise stated. 


\section{Introduction}

Preterm birth is the leading cause of neonatal death and is associated with significant perinatal morbidity and lifelong health consequences [1]. Preterm birth is common and accounts for approximately $10 \%$ of births worldwide [1]. At least half of all preterm births are the result of spontaneous onset of labour or pre-labour rupture of membranes [2]. Despite considerable research efforts there is no effective treatment to stop preterm labour once it has established and current management focuses on prevention [3, 4]. In recent years, specialised preterm birth clinics have developed due to a growing understanding of risk factors for preterm birth and the importance of risk stratification to guide the use of interventions to prevent preterm labour [5]. To the best of our knowledge, the first modern-day preterm birth clinic was established in the United Kingdom (UK) in 1998.

Preterm birth clinics provide focused and specialised obstetric care to asymptomatic women at increased risk of preterm birth due to their obstetric or gynaecological history. The key components include addressing modifiable risk factors (such as advice on becoming smoke-free, and screening and treating infection), surveillance of cervical length by transvaginal ultrasound scan through the midtrimester, and providing evidence-based interventions when indicated. The use of transvaginal cervical length assessment and quantitative fetal fibronectin have been proven to aid prediction of spontaneous preterm birth in asymptomatic high risk women and can be used to guide management decisions $[6,7]$. Interventions such as vaginal progesterone and cervical cerclage have been shown to reduce spontaneous preterm birth and associated neonatal morbidity in asymptomatic, high risk women who develop a sonographic short cervix in the mid-trimester [8-10].

Although there is good evidence to support many of the practices that occur in preterm birth clinics, specific evidence to support the utility of preterm birth clinics as a whole is still evolving [5]. Two previous systematic reviews have attempted to assess the efficacy of preterm birth clinics in reducing spontaneous preterm birth and improving neonatal outcomes [11, 12]. Neither found conclusive evidence to either support or refute the efficacy of specialised preterm birth clinics compared to standard antenatal care $[11,12]$. However, both acknowledged the limited number of studies in this field; only five were randomised controlled trials, all of which were conducted prior to 1990 and no longer reflect practice in modern-day preterm birth clinics. It is unlikely that further randomised controlled trials will be carried out due to the multi-faceted and complex nature of the intervention [5]. Despite the lack of direct evidence to support the use of preterm birth clinics, the poor outcomes from preterm birth, the availability of multiple evidenced-based interventions, and the ability to provide coordinated and individualised care provide sufficient justification for resourcing these clinics [5]. Preterm birth clinics have become standard care in many countries and are recommended in the UK [13].

\section{Rationale}

Until recently there were no national or international guidelines on the protocols and care pathways to be used in preterm birth clinics, and practice is often based on local expert opinion. The newly released (2019) 'Reducing Preterm Birth: Guidelines for Commissioners and Providers' from the UK Preterm Clinical Network provides guidance on referral pathways for preterm birth prevention [13]. This includes recommendations on timing and frequency of cervical length assessments and use of quantitative fetal fibronectin testing, along with management options including cervical cerclage, progesterone and cervical pessary, with reference to the National Institute for Health and Care Excellence (NICE) Guidelines for preterm birth [13, 14].

This systematic review aims to assess the referral criteria and investigations and interventions offered in preterm birth clinics internationally and the planned timing and frequency of review. It does not attempt to prove the efficacy of preterm clinics as it has already been established that there is currently inadequate evidence available $[11,12]$. The results of this systematic review will be useful for future work in improving consistency in care in both established and new preterm birth clinics. This will in turn allow results from future highquality observational studies to be more accurately synthesised in systematic review and meta-analyses to assess the efficacy of preterm birth clinics in reducing spontaneous preterm birth and improving offspring outcome.

\section{Objectives}

This systematic review has four objectives:

1. To assess the eligibility criteria used for referral to preterm birth clinics.

2. To assess the types of investigations offered in preterm birth clinics.

3. To assess the types of interventions offered in preterm birth clinics.

4. To assess the planned frequency and timing of review in preterm birth clinics.

\section{Methods}

\section{Protocol and registration}

The protocol was prospectively registered with the PROSPERO International Prospective Register of Systematic Reviews in May 2019, registration number CRD24019131470, available at https://www.crd.york.ac. uk/prospero/display_record.php?RecordID $=131470$. This systematic review has been conducted in line with the 
standard Preferred Reporting Items for Systematic Reviews and Meta-Analyses (PRISMA) statement and written according to the PRISMA checklist of items to include when reporting a systematic review [15].

\section{Eligibility criteria}

All studies on preterm birth clinics were eligible for inclusion, including those that assessed a clinic indirectly i.e. by assessing another intervention in a high risk population cared for in a preterm birth clinic. Preterm birth clinics are also known as preterm birth prevention clinics, preterm surveillance clinics, specialised preterm birth clinics, dedicated preterm birth clinics, miscarriage follow-up clinics and specialised antenatal clinics. There is no comparator group in this review due to the nature of the research objectives. Studies on other types of specialised antenatal clinics such as for multiple pregnancy, hypertension and diabetes were excluded.

There were no restrictions placed on the types of studies eligible for inclusion and both quantitative and qualitative research methods were included. Examples of study designs include randomised controlled trials, cohort studies, case-controlled studies, cross-sectional studies, interviews, surveys and focus groups. Studies were restricted to those published in the English language, for feasibility, and to publications from 1998 onwards, as this is when the first modern-day preterm birth clinic was established.

The primary outcome measures are:

1. Eligibility criteria for referral (for example, previous spontaneous preterm birth prior to a specified gestation, previous cervical surgery of specific type or depth of excision).

2. Types of investigations offered, defined as any test arranged or carried out from the clinic with the aim of reducing the risk of spontaneous preterm birth or improving perinatal outcomes from preterm birth (for example, urine culture, urogenital swabs, cervical length ultrasound, fetal fibronectin). Investigations that form part of standard antenatal care that are not aimed at reducing the risk of spontaneous preterm birth were excluded (for example, aneuploidy screening, fetal anatomy scan).

3. Types of interventions offered, defined as any surgical, medical or non-medical therapy used with the aim of reducing the risk of spontaneous preterm birth (for example, cervical cerclage, progesterone, cervical pessary) or with the aim of improving perinatal outcomes for babies that are born preterm (for example, antenatal corticosteroids, hospital admission).

The secondary outcomes measures are:
4. Timing of planned first and last clinic visit (measured in weeks and days of gestation).

5. Frequency of planned clinic review (measured in number of days or weeks).

\section{Information sources}

The MEDLINE, Embase, PsycINFO, CENTRAL and CINAHL databases were searched on 1 May 2019. Additional studies were identified by hand-searching reference lists of included publications.

\section{Search}

A comprehensive search strategy was developed using the Peer Review of Electronic Search Strategies (PRESS) Guidelines [16] and was adapted for each of the five databases. The search strategy utilised keyword terms for a preterm birth clinic, and $\mathrm{MeSH}$ terms for outpatient pregnancy care combined with $\mathrm{MeSH}$ terms for preterm birth, pregnancy complications or high risk pregnancy. A human filter was applied along with limits for the English language and for references published from 1998 onwards. The MEDLINE search is available in Additional file 1: Table S1.

\section{Study selection}

References identified from each database search were imported into EndNote X8 referencing software [17] and then into Covidence systematic review software [18]. Duplicates were identified and excluded. References were screened independently by two reviewers for potential eligibility based on the title and abstract. Full-text articles were retrieved for references that appeared to be relevant and these were also independently assessed for inclusion by two reviewers. Discrepancies were resolved through discussion. Records were combined if they described the same study, e.g. conference abstracts with full-text articles; and studies that had been updated. For updated studies, the most recent record was used as the study identifier to describe both the original and updated study, and was used for the majority of data collection. Studies were also grouped when there was more than one study describing an individual clinic, with the most relevant study selected following discussion between two investigators. This selected study was used as the study identifier and for the majority of data collection, with the additional studies used for missing data. This approach was necessary to prevent over-representation of clinics that were described in more than one study. All studies that reported on multiple (named or unnamed) clinics were included at this stage for simplicity and over-representation was addressed later in synthesis.

\section{Data collection process}

Electronic data collection forms were used to extract and record data from included studies. Data collection was 
performed by one reviewer and cross-checked by a second reviewer. Authors were contacted for the names and locations of included preterm birth clinics when this was not reported.

\section{Data items}

Primary and secondary outcomes previously specified were collected. Other data items include study source information and funding details, study design, study timeframes, demographic details, risk factors for spontaneous preterm birth, and spontaneous preterm birth rates.

\section{Risk of bias and quality assessments}

Two reviewers assessed the methodological quality of included studies. The Cochrane Risk of Bias Tool [19] was used for randomised controlled trials, the NewcastleOttawa Scale [20] for cohort, case controlled studies and other observational studies, the modified Newcastle-Ottawa Scale [21] for cross-sectional studies and the Critical Appraisal Skills Programme (CASP) Checklist [22] for qualitative studies.

\section{Summary measures}

Primary and secondary outcomes are described as proportions.

\section{Synthesis of results}

The majority of studies included UK based preterm birth clinics, and some reported on multiple clinics. To ensure we avoided over-representation of clinics described in more than one study, authors of UK studies that reported on unnamed clinics were approached [23-26]. This allowed us to assess whether the largest and most comprehensive study on preterm birth clinics (Care 2019) [23] included all UK clinics described in other studies. All but four clinics in the Care 2019 study were identified and alternative studies including them were excluded from synthesis [25-35]. Of the four clinics reported anonymously in the Care 2019 study, three are also believed to have been reported elsewhere and so these studies were also excluded [24, 36]. Data from Care 2019 were amalgamated with data from remaining studies, all of which reported on individual clinics outside of the UK, to provide an overall synthesis for the primary and secondary outcomes. A narrative synthesis is provided, structured around the outcome measures, with information also presented in tables. No meta-analysis was performed.

\section{Results}

\section{Study selection}

The study selection process is detailed in Fig. 1. Of the 1293 records identified from the search strategy, 32 fulfilled eligibility criteria. Three of these were conference abstracts for included full text articles [37-39]. One study had been updated and the two publications were combined [23, 40]. A further eight were additional studies reporting on individual clinics already represented by another included study [41-48] (detailed in Table 1). Twenty studies were therefore included in the main analysis.

\section{Study characteristics}

Of the 20 included studies, 15 were full text articles [23, $24,27-29,33,34,49-56]$ and five were conference abstracts [26, 30-32, 36]. Fourteen studies reported on an individual clinic [27-33, 36, 49-53, 56] and six studies reported on multiple clinics [23, 24, 26, 34, 54, 55]. There were a variety of study designs; seven retrospective audits [26, 28-32, 51], three prospective observational studies $[24,36,55]$, two cross-sectional studies [23, 49], two prospective cohort studies [54,56], two retrospective cohort studies [50, 52], two other retrospective observational studies [27, 34], one randomised controlled trial [53], and one qualitative interpretive study [33]. A total of 39 clinics were assessed in data synthesis; 33 clinics $(87 \%)$ were in the UK, two in America, two in Australia, and one each in Germany and Italy.

\section{Risk of bias and quality assessments}

Results of the methodological quality assessments are shown in Additional file 1: Tables S2-S5. Methodological quality was mixed with studies of low, medium and high quality.

\section{Results of individual studies}

The study characteristics and primary and secondary outcomes are summarised in Table 2 for studies on individual clinics, and in Table 3 for studies reporting on multiple clinics.

\section{Synthesis of results}

Data from 39 clinics were combined to assess the primary and secondary outcomes; 33 UK based clinics from Care $2019^{23}$ and six clinics from individual clinic studies outside of the UK [7, 49-53]. Outcome data was incomplete for some clinics, thus the number of clinics assessed for each outcome varies.

Preterm birth clinic referral criteria is described in Table 4. All clinics accepted referrals for women with a previous spontaneous preterm birth, however the gestation of previous preterm birth varied. Just over half (20/ $38,53 \%)$ set a threshold of $<34$ weeks for review. Previous late miscarriage or mid-trimester loss was the second most common referral criteria reported in 34/38 (89\%) clinics. Most clinics also accepted referrals for women with previous cervical surgery (33/38, 87\%), although there was variation in the type of surgery and numbers of excisional biopsies required (Table 4). 


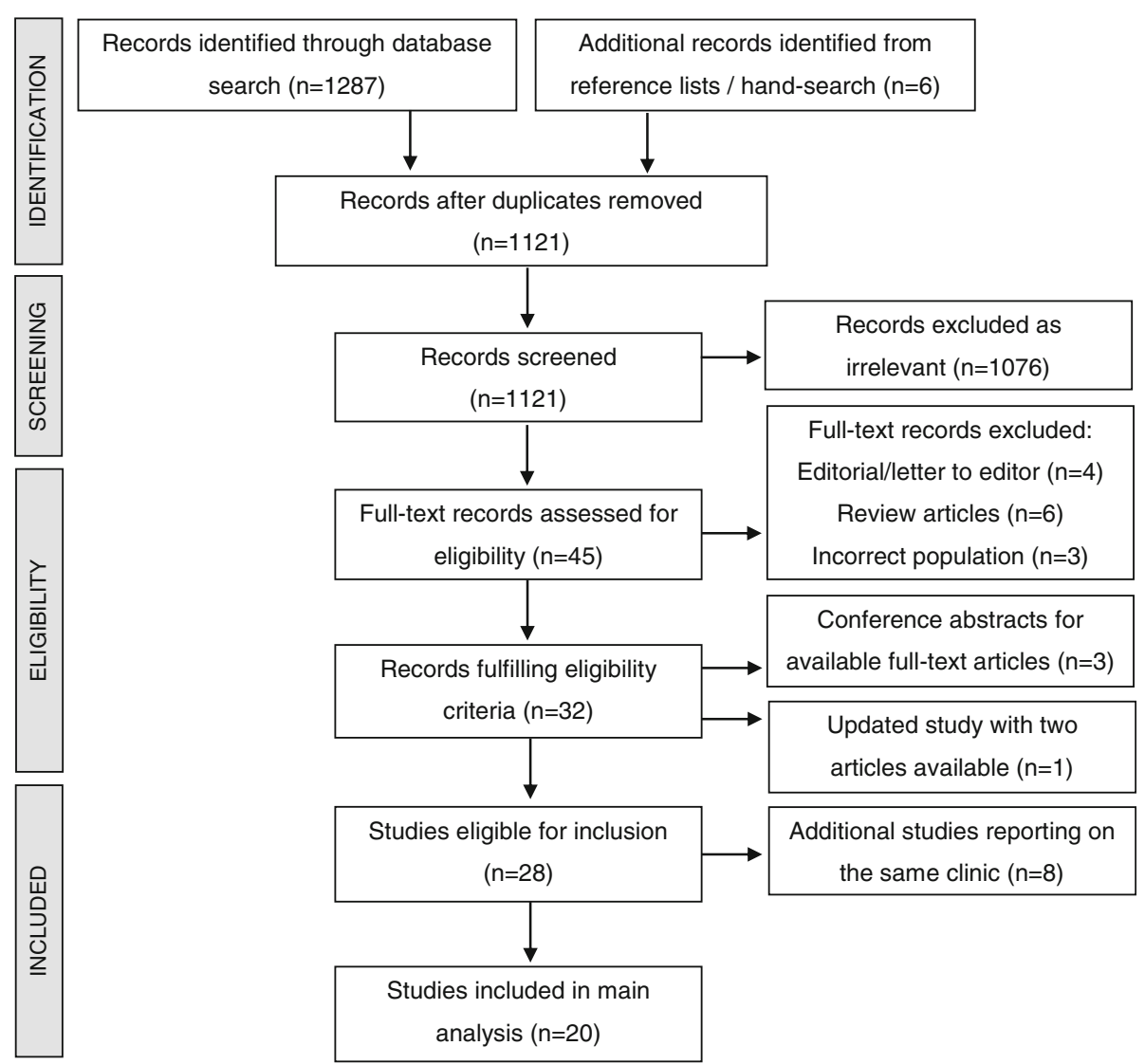

Fig. 1 PRISMA flow chart of study selection

Data on the types of investigations offered were available for 28 clinics (22 UK, 6 non-UK). All clinics performed transvaginal cervical length ultrasound scans, however use of additional investigations was variable. Urogenital swabs were the second most common investigation performed, with 16/28 (57\%) clinics routinely offering this. Fetal fibronectin was used as a risk assessment tool in asymptomatic women in some clinics (8/ 28, 29\%). Other investigations included urine culture, rectal culture for Group B streptococcus, serum thyroid

Table 1 Grouping of studies when more than one study reports on an individual clinic

\begin{tabular}{lll}
\hline Main study & $\begin{array}{l}\text { Additional studies } \\
\text { on the same clinic }\end{array}$ & $\begin{array}{l}\text { Name and location } \\
\text { of preterm birth clinic }\end{array}$ \\
\hline Bolt 2011 & $\begin{array}{l}\text { Khambay 2012 } \\
\text { Duhig 2009 } \\
\text { Min 2016 } \\
\text { Smout 2010 }\end{array}$ & $\begin{array}{l}\text { Guys and St Thomas' Hospital, } \\
\text { London, United Kingdom }\end{array}$ \\
Ivandic 2018 & $\begin{array}{l}\text { Alfirevic 2013 } \\
\text { Care AG 2014 } \\
\text { Care A 2014 }\end{array}$ & $\begin{array}{l}\text { Liverpool Women's Hospital, } \\
\text { Liverpool, United Kingdom }\end{array}$ \\
Karkhanis 2012 & Raouf 2009 & $\begin{array}{l}\text { Birmingham Heartlands Hospital, } \\
\text { Birmingham, United Kingdom }\end{array}$ \\
\hline
\end{tabular}

${ }^{\mathrm{a}}$ Conference abstract only stimulating hormone and alkaline phosphatase which were each described in one clinic.

There were differences in how interventions aimed at reducing the risk of spontaneous preterm birth were reported. Table 5 lists the range of interventions offered for the six clinics outside of the UK, and separately describes the primary treatment choice for a sonographic short cervix for the 33 clinics within the UK where this information was available. Data on the range of interventions offered in UK clinics was not available for synthesis. Cervical cerclage was offered in all clinics outside of the UK $(6 / 6,100 \%)$. Progesterone was also offered in all clinics, as vaginal progesterone in $4 / 6$ (67\%) and intramuscular 17-alpha hydroxyprogesterone caproate (17OHP-C) in the remaining two clinics, both of which were in America. Within UK based preterm birth clinics, the primary treatment choice for women with a sonographic short cervix was cervical cerclage in $10 / 33$ clinics $(30 \%)$, vaginal progesterone in $6 / 33(18 \%)$ and cervical pessary in $1 / 33(3 \%)$. An additional 10/33 clinics $(30 \%)$ reported utilisation of multiple first-line treatment options, and 6/33 (18\%) used a combination of treatment, usually cervical cerclage and vaginal progesterone. 
Table 2 Characteristics of included studies reporting on an individual clinic

\begin{tabular}{lllll}
\hline Study details & $\begin{array}{l}\text { Characteristics of women } \\
\text { cared for in the clinic and } \\
\text { spontaneous preterm birth }\end{array}$ & $\begin{array}{l}\text { Eligibility criteria for } \\
\text { referral to the clinic }\end{array}$ & $\begin{array}{l}\text { Investigations and } \\
\text { interventions offered }\end{array}$ & $\begin{array}{l}\text { Timing and } \\
\text { frequency of review }\end{array}$
\end{tabular}

rate

\section{Bolt 2011}

Retrospective observational study.

12 month period, dates not reported.

Guys and St Thomas' Hospital, London, UK.

Primary and secondary outcome data also obtained from Min 2016, Khambay 2012 and Duhig 2009.

\section{Ivandic $\mathbf{2 0 1 8}$}

Retrospective audit. January 2013 - December 2017. Liverpool Women's Hospital, Liverpool, UK.

Primary and secondary outcome data also obtained from Care AG 2014 and Alfirevic 2013.

147 women; White $45 \%$,
Black 44\%, Asian 4\%, other
$5 \%$ and unknown $3 \%$.
Risk factors for spontaneous
preterm birth: previous
preterm birth > 24 weeks
$37 \%$, previous late
miscarriage $35 \%$, LLETZ
$13 \%$, cone biopsy $11 \%$,
previous cerclage $16 \%$,
current cerclage $27 \%$.
Spontaneous preterm birth
rate < 37 weeks $18 \%$.
rate $<37$ weeks $18 \%$.
129 women; White $85 \%$, Black African 3\%, Asian 2\%, Arab 3\% and other $7 \%$. Risk factors for spontaneous preterm birth: previous preterm birth or PPROM < 34 weeks 76\%, LLETZ 21\%, knife cone biopsy $9 \%$. Spontaneous preterm birth rate $<37$ weeks $50 \%$, < 34 weeks $29 \%$.

Previous preterm birth
$<37$ weeks.
Previous PPROM < 37
weeks.
Previous late
miscarriage $16-24$
weeks.
Extensive cervical
surgery e.g. LLETZ,
cone biopsy,
trachelectomy.
Uterine abnormality.
Cervical length $<25$
mm on transvaginal
scan.
Previous cervical
cerclage.

Previous spontaneous preterm birth at 1634 weeks.

Previous PPROM at 16-34 weeks.

Significant cervical surgery defined as $\geq 2$ LLETZ or knife cone biopsy.

Uterine abnormalities. Incidental finding of short cervix on ultrasound.

Following an episode of threatened preterm labour.

180 women; ethnicity not reported.

Risk factors for spontaneous preterm birth: previous preterm labour or midtrimester loss $88 \%$. Spontaneous preterm birth rate $<37$ weeks $32 \%$.

63 women; ethnicity not reported.

Risk factors for spontaneous preterm birth: previous late miscarriage or preterm delivery < 34 weeks $40 \%$, previous deep cervical treatment $43 \%$, uterine anomaly $8 \%$.

Spontaneous preterm birth
Previous preterm birth. Previous mid-trimester loss.

Previous preterm delivery $<34$ weeks. Previous late miscarriage. Previous deep cervical treatment. Uterine anomalies.

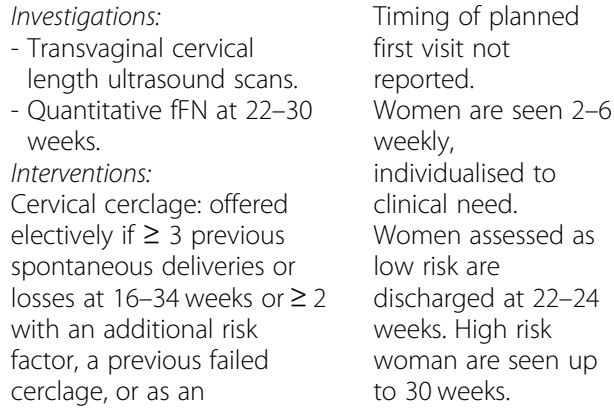

Timing of planned first visit not reported.

Women are seen 2-6 weekly, individualised to clinical need.

Women assessed as low risk are discharged at 22-24 weeks. High risk woman are seen up to 30 weeks.

- Hospital admission.

- Antibiotics if infection suspected.

- Tocolysis (nifedipine) if contracting.

- Betamethasone.

Investigations:

- Transvaginal cervical length ultrasound scans.

Interventions:

Treatment is offered if transvaginal cervical length $<3$ rd centile for gestational age, including: - Cervical pessary.

- Vaginal progesterone.

- Cervical cerclage.

Investigations:

- Transvaginal cervical length ultrasound scans.

- Midstream urine.

- Low vaginal swabs.

Interventions:

- Cervical cerclage.

- Vaginal progesterone.

- Combined treatment.

Investigations:

- Transvaginal cervical length ultrasound scans. Interventions:

- Cervical cerclage.
The first visit is planned for 16 weeks, or earlier if there is a history of significant cervical surgery or cerclage in a previous pregnancy. Women are seen 1-4 weekly depending on the initial cervical length and the gestational age of previous preterm births.

Women are discharged at 28 weeks.

The first visit is planned for 16 weeks.

Frequency of review is not reported. Women are discharged at 34 weeks.

Not reported.
Chelsea and Westminster Hospital, London, UK. 
Table 2 Characteristics of included studies reporting on an individual clinic (Continued)

\begin{tabular}{lllll}
\hline Study details & $\begin{array}{l}\text { Characteristics of women } \\
\text { cared for in the clinic and } \\
\text { spontaneous preterm birth } \\
\text { rate }\end{array}$ & $\begin{array}{l}\text { Eligibility criteria for } \\
\text { referral to the clinic }\end{array}$ & $\begin{array}{l}\text { Investigations and } \\
\text { interventions offered }\end{array}$ & $\begin{array}{l}\text { Timing and } \\
\text { frequency of review }\end{array}$ \\
\end{tabular}

rate

\section{Kindinger 2013}

Retrospective audit (conference abstract only).

January 2011 - January 2013.

St Mary's Hospital, London, UK.

\section{Burul 2014}

Retrospective audit (conference abstract only).

January 2005 - December 2012.

University College London

Hospital, London, UK.

\section{Grant 2016}

Prospective observational study (conference abstract only). January 2014 - January 2016 Royal Derby Hospital, Derby, UK.

8. O'Brien 2010

Qualitative interpretive study. Study dates not reported. Manchester, UK.

rate $<37$ weeks $16 \%$.

160 women; ethnicity not reported.

Risk factors for spontaneous preterm birth: previous cervical treatment $43 \%$, previous preterm birth $<34$ weeks $21 \%$, previous midtrimester loss 26\%, uterine anomalies $5 \%$, multiple pregnancy $3 \%$. Spontaneous preterm birth rate $<34$ weeks $8 \%$

125 women; ethnicity and risk factors for spontaneous preterm birth not reported. Spontaneous preterm birth rate not reported, but median gestation at delivery was $35^{+2}$ weeks.

146 women; ethnicity not reported.

Risk factors for spontaneous preterm birth: previous preterm birth < 37 weeks $36 \%$, previous second trimester miscarriage 13\%, previous failed rescue cerclage $1 \%$, previous LLETZ $49 \%$, previous cone biopsy

$2 \%$, previous cervical biopsies 2\%, medical history (not further defined) 4\%. Spontaneous preterm birth rate $<37$ weeks $25 \%$.

14 women; White British 93\%, Black Caribbean 7\%. Risk factors for spontaneous preterm birth and spontaneous preterm birth rate not reported.
Previous preterm birth $<34$ weeks.

Previous mid-trimester loss.

Previous cervical treatment.

Uterine anomalies. Multiple pregnancy.

Not reported.

nvestigations:

- Not reported.

Interventions:

- Cervical cerclage.

Previous preterm birth $<37$ weeks.

Previous second trimester miscarriage. Previous failed rescue cerclage.

Previous LLETZ.

Previous cone biopsy.

Previous cervical biopsies.

Medical history (not further defined).

Previous preterm birth. Cervical surgery or other gynaecological procedures that increases the risk of cervical incompetence (not further defined).
Investigations:

- Transvaginal cervical length ultrasound scans. Interventions:

- Cervical cerclage.

- Vaginal progesterone.

- Aspirin.

- Antibiotics.

- Activity restriction.

- Hospital admission.

\section{Turitz 2016}

Cross-sectional study. November 2009 - June 2013. Hospital of the University of Pennsylvania, Pennsylvania, United States of America.
218 women; African American 83\%, Caucasian $12 \%$, other $6 \%$.

Risk factors for spontaneous preterm birth: previous second trimester loss 39\%, previous spontaneous preterm birth < 37 week $71 \%$.

Spontaneous preterm birth rate $<37$ weeks $36 \%$.

70 preterm birth clinic
Previous spontaneous preterm birth $<37$ weeks.

Previous second trimester loss 16-24 weeks.

Previous spontaneous
Investigations:

- Transvaginal cervical length ultrasound scans. Interventions:

- IM 17OHP-C for all.

- Cervical cerclage also recommended if cervical length $\leq 15 \mathrm{~mm}$ or previous preterm birth < 34 weeks.

Investigations:
Not reported

Not reported

Not reported

Timing of planned visit is not reported, however it is noted that women are encouraged to attend as soon as they become pregnant. Frequency of review is weekly, fortnightly or monthly depending on individual needs. Timing of last visit is not reported.

Not reported. 
Table 2 Characteristics of included studies reporting on an individual clinic (Continued)

\begin{tabular}{|c|c|}
\hline Study details & $\begin{array}{l}\text { Characteristics of women } \\
\text { cared for in the clinic and } \\
\text { spontaneous preterm birth } \\
\text { rate }\end{array}$ \\
\hline $\begin{array}{l}\text { Retrospective cohort study. } \\
\text { Usual care patients June } 2002 \text { - } \\
\text { June 2010, preterm birth clinic } \\
\text { patients 2008-2010. } \\
\text { Utah, United States of America. }\end{array}$ & $\begin{array}{l}\text { patients; Caucasian } 83 \% \text {. } \\
\text { ( } 153 \text { usual-care patients). } \\
\text { Risk factors for spontaneous } \\
\text { preterm birth: previous } \\
\text { spontaneous preterm birth } \\
<35 \text { weeks } 100 \% \text {. } \\
\text { Spontaneous preterm birth } \\
\text { rate < } 37 \text { weeks } 49 \% \text { in } \\
\text { preterm birth clinic patients } \\
\text { (63\% in usual care patients). }\end{array}$ \\
\hline
\end{tabular}

\section{Hughes 2017}

Retrospective audit. 2004-2013.

Royal Women's Hospital, Melbourne, Australia.

\section{Newnham 2017}

Prospective population-based cohort study.

2009 - December 2015

(November 2014 - December 2015 for assessment of preterm birth clinic)

Perth, Western Australia.

Eligibility criteria for
referral to the clinic

Investigations and

interventions offered

Timing and

frequency of review

756 women; ethnicity not reported.

Risk factors for spontaneous preterm birth: previous spontaneous preterm birth 54\%, previous cervical surgery $24 \%$, uterine malformations 11\%, incidental finding of short cervix 9\%.

Spontaneous preterm birth rate $<37$ weeks $21 \%$. surgery: $\geq 1$ cold knife

154 women cared for in the preterm birth clinic, but data on 92 concluded pregnancies reported only (233,527 births in whole statewide cohort); ethnicity not reported.

Risk factors for spontaneous preterm birth: previous early preterm birth $67 \%$, recurrent pregnancy losses 26\%, previous cone biopsy or other ablative procedures of the cervix 14\%, uterine anomalies 11\%, autoimmune conditions $11 \%$, placental risk factors $10 \%$.

Preterm birth < 37 weeks $32 \%$ (spontaneous preterm birth rate not reported separately).

106 women; ethnicity not

preterm birth $<35$
weeks.

preterm
weeks.

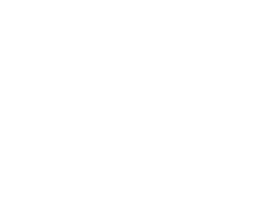

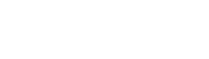

\section{Previous spontaneous} preterm birth.

Previous mid-trimester loss.

Previous cervical cone biopsy or $\geq 2$

LLETZ.

$\geq 3$ surgical

terminations of

pregnancy or $\geq 4$

dilatation and

curettage procedures. Incidental finding of a short cervix $<25 \mathrm{~mm}$ on transvaginal scan in the mid-trimester. Uterine malformation.

Previous early preterm birth.

Recurrent pregnancy loss.

Previous cone biopsy or other ablative procedure of the cervix.

Uterine anomalies. Previous stillbirth or neonatal death.

Autoimmune conditions.

Placental risk factors.
- Transvaginal cervical length ultrasound scans.

- Vaginal swab for bacterial vaginosis.

- Urine culture.

- fFN only if symptoms. Interventions:

- IM 170HP-C for all.

- Cervical cerclage if cervical length $<25 \mathrm{~mm}$ at $<22$ weeks

If cervical length shortening is detected > 22 weeks:

- Hospital admission.

- Activity restriction.

- Tocolysis (indomethacin) if contracting.

- Betamethasone.

Investigations:

- Transvaginal cervical length ultrasound scans.

- Cervical swabs for abnormal flora at each visit and for chlamydia at the first visit.

- Serum thyroid stimulating hormone and alkaline phosphatase at the first visit.

- fFN at the final visit.

Interventions:

Women are offered treatment if cervical length $<25 \mathrm{~mm}$, options include:

- Vaginal progesterone.

- Cervical cerclage.

- Arabin pessary (as part of a study only).

Appropriate antimicrobials as indicated.

planned for 10-18 weeks.

Frequency of review is six weekly with additional visits as clinically indicated (every 1-2 weeks if the cervix shortens). Women are discharged at 28-32 weeks.

The first visit is planned for 14 weeks.

Women are seen fortnightly. Women are discharged at 26 weeks.

Timing of planned Investigations:

- Transvaginal cervical length ultrasound scans. Interventions:

- Vaginal progesterone.

- Cervical cerclage.

- Mental health support.

- 'Medical interventions' not further specified. visit is not reported, however the median gestational age at first visit was $13^{+6}$ weeks.

Frequency of review and timing of last visit is not reported. 
Table 2 Characteristics of included studies reporting on an individual clinic (Continued)

\begin{tabular}{|c|c|c|c|c|}
\hline Study details & $\begin{array}{l}\text { Characteristics of women } \\
\text { cared for in the clinic and } \\
\text { spontaneous preterm birth } \\
\text { rate }\end{array}$ & $\begin{array}{l}\text { Eligibility criteria for } \\
\text { referral to the clinic }\end{array}$ & $\begin{array}{l}\text { Investigations and } \\
\text { interventions offered }\end{array}$ & $\begin{array}{l}\text { Timing and } \\
\text { frequency of review }\end{array}$ \\
\hline $\begin{array}{l}\text { Retrospective cohort study. } \\
\text { October } 2008 \text { - December } 2014 . \\
\text { Marburg, Germany. }\end{array}$ & $\begin{array}{l}\text { reported. } \\
\text { Risk factors for spontaneous } \\
\text { preterm birth: previous } \\
\text { preterm birth < } 37 \text { weeks } \\
33 \% \text {, previous surgical } \\
\text { conisation } 19 \% \text {, previous } \\
\text { cervical cerclage for a short } \\
\text { cervix } 12 \% \text {, short cervix }< \\
3 r d \text { centile in current } \\
\text { pregnancy } 48 \% \text {. } \\
\text { Spontaneous preterm birth } \\
\text { rate }<37 \text { weeks } 44 \%,<34 \\
\text { weeks } 28 \% \text {. }\end{array}$ & $\begin{array}{l}\text { or mid-trimester loss } \\
\text { at } 16-37 \text { weeks. } \\
\text { Previous surgical } \\
\text { conisation. } \\
\text { Previous cerclage for a } \\
\text { short cervix. } \\
\text { Short cervical } \\
\text { length }<3 r d \text { centile } \\
\text { on transvaginal scan } \\
\text { in current pregnancy. }\end{array}$ & $\begin{array}{l}\text { - Transvaginal cervical } \\
\text { length ultrasound scans. } \\
\text { Interventions: } \\
\text { For singleton pregnancies } \\
\text { with a short cervix <3rd } \\
\text { centile: } \\
\text { - Cervical pessary. } \\
\text { - Vaginal progesterone. } \\
\text { - Cervical cerclage. }\end{array}$ & $\begin{array}{l}\text { first visit and } \\
\text { frequency of review } \\
\text { not reported. } \\
\text { Women are } \\
\text { discharged at } 32 \\
\text { weeks. }\end{array}$ \\
\hline $\begin{array}{l}\text { 14. Danti } 2014 \\
\text { Randomised controlled trial. } \\
\text { May } 2000 \text { - May } 2003 \text {. } \\
\text { Hospital of the University of } \\
\text { Brescia and University of Turin, } \\
\text { Italy. }\end{array}$ & $\begin{array}{l}87 \text { women; Caucasian } 95 \% \text {, } \\
\text { others not reported. } \\
\text { Risk factors for spontaneous } \\
\text { preterm birth: short cervix } \\
\leq 25 \mathrm{~mm} \text { at } 24-32 \text { weeks } \\
100 \% \text {, previous preterm } \\
\text { delivery or PPROM 14\%, } \\
\text { previous mid-trimester mis- } \\
\text { carriages } 3 \% \text {, uterine anom- } \\
\text { alies (bifid uterus, uterine } \\
\text { septum, myoma) 3\%, previ- } \\
\text { ous cervical surgery } 1 \% \text {. } \\
\text { Spontaneous preterm birth } \\
\text { rate }<37 \text { weeks } 15 \% \text {. }\end{array}$ & $\begin{array}{l}\text { Previous preterm } \\
\text { labour and/or PPROM. } \\
\text { Previous mid-trimester } \\
\text { miscarriage. } \\
\text { Previous cervical } \\
\text { insufficiency. } \\
\text { Previous cervical } \\
\text { surgery. } \\
\text { Uterine fibromyoma. } \\
\text { Uterine malformations } \\
\text { Clinical suspicion of } \\
\text { cervical shortening. }\end{array}$ & $\begin{array}{l}\text { Investigations: } \\
\text { - Transvaginal cervical } \\
\text { length ultrasound scans. } \\
\text { - Vaginal culture for } \\
\text { trichomonas, aerobic and/ } \\
\text { or anaerobic bacteria, } \\
\text { chlamydia. } \\
\text { - Rectal samples for beta } \\
\text { haemolytic streptococcus. } \\
\text { Interventions: } \\
\text { - Cervical cerclage. } \\
\text { - Vaginal progesterone. } \\
\text { - Targeted antibiotic } \\
\text { therapy for positive } \\
\text { cultures. } \\
\text { Tocolysis (nifedipine) as the } \\
\text { study intervention } \\
\text { (compared to placebo). }\end{array}$ & $\begin{array}{l}\text { The first visit is } \\
\text { planned for } 14 \\
\text { weeks. } \\
\text { Frequency of } \\
\text { planned review not } \\
\text { reported. } \\
\text { Women are } \\
\text { discharged at } 34 \\
\text { weeks. }\end{array}$ \\
\hline
\end{tabular}

PPROM premature pre-labour rupture of membranes, LLETZ large loop excision of the transformation zone, fFN fetal fibronectin, IM intramuscular, 17OHP-C 17alpha hydroxyprogesterone caproate, UK United Kingdom

Various measures were used to define the threshold for treatment of a 'short' cervix. The most common threshold was a cervical length of $<25 \mathrm{~mm}(21 / 38,53 \%)$. A cervical length of $<15 \mathrm{~mm}$ or use of centile charts were used less frequently $(2 / 38,5 \%$ and $6 / 38,16 \%$ respectively). A further $4 / 38$ clinics (11\%) used a combination of thresholds with centile charts and/or a cervical length of $<25 \mathrm{~mm}$. Results from the QUiPP App, which combines clinical history, cervical length measurements and fetal fibronectin [55] were used by $4 / 38$ (11\%) clinics to determine the need for treatment for a short cervix. One clinic reported using an 'other' threshold and data were unavailable for another.

The use of additional interventions such as hospital admission, antenatal corticosteroid therapy and antimicrobials for high risk, asymptomatic women was not consistently reported across studies and these data were not available from the large surveys of practice in the UK; thus accurate synthesis of information was not possible. Data on additional interventions are provided in Tables 2 and 3 where this was reported in individual studies.

Many clinics also provided routine lifestyle recommendations. Of the 22 clinics (all in the UK), where these data were available, almost half $(10 / 22,45 \%)$ routinely advised restriction of physical activity, 6/22 (27\%) recommended stopping work, 9/22 (41\%) advised refraining from sexual intercourse and 6/22 (27\%) made dietary recommendations. No clinic recommended routine bed rest and $8 / 22$ (36\%) clinics reported that no additional advice was given.

Table 6 describes the planned timing of preterm birth clinic visits. Data were available for the planned first appointment for 35 clinics (32 UK, 3 non-UK), and for planned last appointment for 26 clinics (22 UK, 4 nonUK). Most clinics planned to see women for their first appointment at 12 to 14 weeks $(14 / 35,40 \%)$ or 15 to 16 weeks $(16 / 35,46 \%)$. The timing of discharge from a preterm birth clinic varied considerably from 24 to 37 weeks. The planned frequency of review was available for 24 clinics (22 UK, 2 non-UK) with the majority $(18 / 24,75 \%)$ individualising this depending on clinical findings. Five clinics $(21 \%)$ reviewed women fortnightly, and one clinic (4\%) four-weekly.

\section{Discussion}

\section{Summary of evidence}

Data was obtained for a number of preterm birth clinics in this systematic review. The majority of clinics were 
Table 3 Characteristics of included studies reporting on multiple clinics

\begin{tabular}{|c|c|c|c|c|}
\hline Study details & $\begin{array}{l}\text { Characteristics of women } \\
\text { cared for in the clinic and } \\
\text { spontaneous preterm birth } \\
\text { rate }\end{array}$ & $\begin{array}{l}\text { Eligibility criteria for } \\
\text { referral to the clinic }\end{array}$ & $\begin{array}{l}\text { Investigations and } \\
\text { interventions offered }\end{array}$ & $\begin{array}{l}\text { Timing and frequency of } \\
\text { review }\end{array}$ \\
\hline $\begin{array}{l}\text { 1. Kindinger } 2016 \\
\text { Retrospective observational } \\
\text { study. } \\
\text { January } 2004 \text { to January } 2014 . \\
\text { Queen Charlotte's Hospital, St } \\
\text { Mary's Hospital and Chelsea }\end{array}$ & $\begin{array}{l}725 \text { women; Caucasian } 66 \% \text {, } \\
\text { Black } 18 \% \text {, Asian } 16 \% \text {. } \\
\text { Risk factors for spontaneous } \\
\text { preterm birth: previous } \\
\text { excisional cervical treatment to } \\
\text { a depth of } \geq 12 \mathrm{~mm} 100 \%\end{array}$ & $\begin{array}{l}\text { Previous preterm } \\
\text { birth }<37 \text { weeks. } \\
\text { Previous mid- } \\
\text { trimester miscarriage } \\
>13 \text { weeks. } \\
\text { Uterine anomaly. }\end{array}$ & $\begin{array}{l}\text { Investigations: } \\
\text { - Transvaginal cervical } \\
\text { length ultrasound } \\
\text { scans. } \\
\text { Interventions: } \\
\text { - Cervical cerclage. }\end{array}$ & $\begin{array}{l}\text { The first visit is planned for } \\
13-16 \text { weeks. } \\
\text { Frequency of planned } \\
\text { review not reported. } \\
\text { Women are discharged at } \\
20-23 \text { weeks. }\end{array}$ \\
\hline
\end{tabular}
and Westminster Hospital: London, UK.

\section{Watson 2017}

Prospective cohort study. April 2012 - November 2016 Guys and St Thomas' Hospital and University College London Hospital; London, UK.

\section{Cohen 2014}

Retrospective audit (conference abstract only). January 2013 - May 2014. St Mary's Hospital and Queen Charlotte's Hospital; London, UK.

\section{Kuhrt 2016}

Prospective observational study.

October 2010 - July 2014. St Thomas' Hospital, Queen Charlotte's Hospital, University College London Hospital, West Middlesex University Hospital; London, UK; Manchester St Mary's Hospital; Manchester, UK.

\footnotetext{
5. Vousden 2015

Prospective observational study.

November 2010 - July 2014.

Fifteen hospitals across the UK nine of which have preterm birth clinics - St Thomas' Hospital, Queen Charlotte's Hospital, University College London Hospital, West Middlesex University Hospital; London; Royal Infirmary of Edinburgh, Edinburgh; Sunderland Royal Hospital; Sunderland; Manchester St
} (women with other risk factors specifically excluded from this study).

Spontaneous preterm birth rate $<37$ weeks $9 \%$, $<34$ weeks $2 \%$.

66 women; White $61 \%$, Black 32\%, Asian/Middle-Eastern 8\% Risk factors for spontaneous preterm birth: previous spontaneous preterm birth or late miscarriage $100 \%$. Spontaneous preterm birth rate $<37$ weeks $35 \%$.

509 women; Caucasian 59\%, Afro-carribean 15\%.

Risk factors for spontaneous preterm birth: previous preterm labour < 34 weeks $26 \%$, previous mid-trimester miscarriage $17 \%$, previous excisional cervical treatment $50 \%$, uterine anomalies $2 \%$, multiple pregnancy $3 \%$.

Spontaneous preterm birth rate $<37$ weeks $11 \%,<34$ weeks $4 \%$.

1249 women.

Ethnicity: White 56\%, Black $29 \%$, Asian 8\%, other 9\%. Risk factors for spontaneous preterm birth: previous spontaneous preterm birth $38 \%$, previous PPROM 19\%, previous late miscarriage $22 \%$, previous cervical surgery $44 \%$, short cervix $<25 \mathrm{~mm} 15 \%$. Spontaneous preterm birth rate $<37$ weeks $15 \%$, < 34 weeks $8 \%$.

54 women; Black 46\%, White $35 \%$, other $19 \%$.

Risk factors for spontaneous preterm birth: previous preterm birth $44 \%$, previous second trimester miscarriage $72 \%$, previous cervical surgery $7 \%$. Spontaneous preterm birth rate $<34$ weeks $11 \%$.

Previous excisiona

cervical treatment to a depth of $\geq 12 \mathrm{~mm}$ (cone biopsy, LLETZ or LEEP).

Previous spontaneous preterm birth $<37$ weeks.

Previous spontaneous late miscarriage between 14 and 24 weeks.

Previous preterm labour < 34 weeks. Previous midtrimester miscarriage. Previous excisional cervical treatment. Uterine anomalies. Multiple pregnancy.

Investigations:

- Transvaginal cervical

length ultrasound

scans.

Interventions:

- Cervical cerclage if cervix $<25 \mathrm{~mm}$.

- Vaginal progesterone.

- Arabin pessary.

Investigations:

- Transvaginal cervical

length ultrasound

scans.

Interventions:

- Cervical cerclage.

- Vaginal progesterone.

Previous

spontaneous

preterm birth $<37$

weeks.

Previous PPROM <

37 weeks.

Previous late

miscarriage 16-24

weeks.

Previous cervical

surgery.

Cervical length $<25$

$\mathrm{mm}$ in the current pregnancy.

Previous preterm birth.

Previous second trimester miscarriage. Previous cervical surgery.
Investigations:

- Transvaginal cervical length ultrasound scans.

- Quantitative fFN.

Interventions:

- Cervical cerclage:

history-indicated if $\geq 3$

late miscarriages or previous spontaneous preterm births $<34$ weeks; ultrasound-indicated if cervix $<25 \mathrm{~mm}$.

- Vaginal progesterone.

Investigations:

- Transvaginal cervical

length ultrasound

scans.

Interventions:

- Cervical cerclage.

- Vaginal progesterone.
Not reported.

Not reported.

Gestation of planned first visit not reported.

Women seen every 2-4 weeks.

Women are discharged at 30 weeks.

Not reported 
Table 3 Characteristics of included studies reporting on multiple clinics (Continued)

\begin{tabular}{lllll}
\hline Study details & $\begin{array}{l}\text { Characteristics of women } \\
\text { cared for in the clinic and } \\
\text { spontaneous preterm birth } \\
\text { rate }\end{array}$ & $\begin{array}{l}\text { Eligibility criteria for } \\
\text { referral to the clinic }\end{array}$ & $\begin{array}{l}\text { Investigations and } \\
\text { interventions offered }\end{array}$ & $\begin{array}{l}\text { Timing and frequency of } \\
\text { review }\end{array}$ \\
\hline
\end{tabular}

Mary's Hospital; Manchester; University Hospital; Coventry; Royal Victoria Infirmary: Newcastle.

\section{Care 2019}

Cross-sectional study (survey). March 2017 - July 2017.

Thirty-three unnamed clinics across the UK (list obtained from authors but not included here).

Primary and secondary outcome data also obtained from Sharp 2014, which was the original study updated by Care 2019.
This study reports on the typical practice of preterm birth clinics, not on individual women cared for in them.

\begin{tabular}{|c|c|c|}
\hline $\begin{array}{l}\text { Percentage of clinics } \\
\text { with each referral } \\
\text { criteria ( } n=32 \text { clinics): } \\
\text { Previous preterm } \\
\text { birth, } 100 \% \text {, at } \\
\text { gestations of: } \\
<37 \text { weeks } 13 \% \text {. } \\
<35 \text { weeks } 3 \% \text {. } \\
<34 \text { weeks } 65 \% \text {. } \\
<32 \text { weeks } 13 \% \text {. } \\
<28 \text { weeks } 3 \% \text {. } \\
\text { Other } 3 \% \text {. }\end{array}$ & 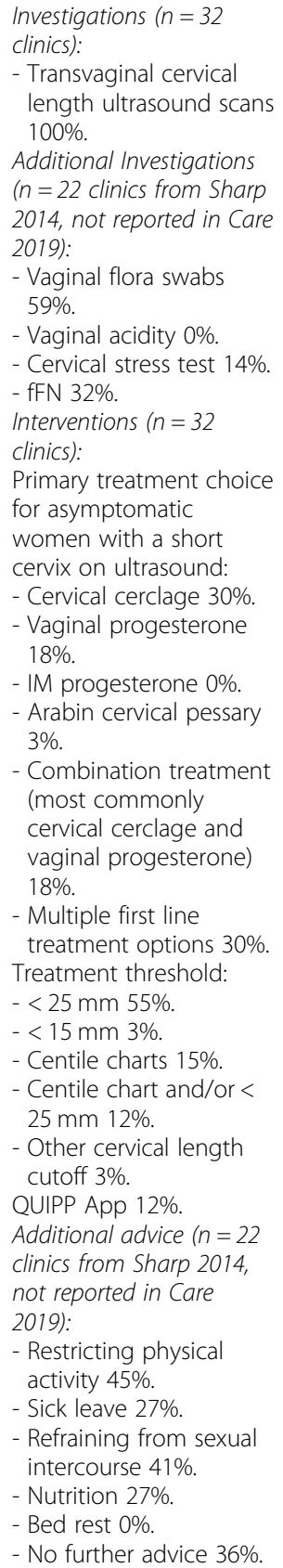 & 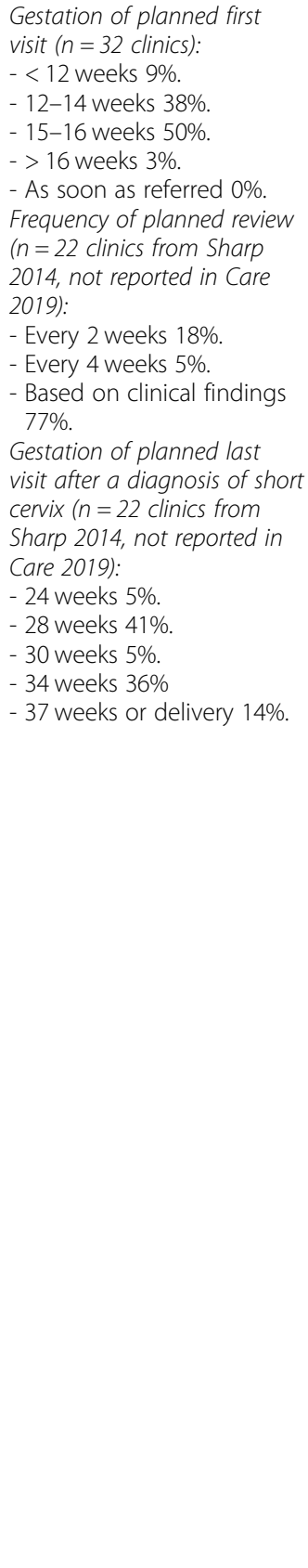 \\
\hline
\end{tabular}

Percentage of clinics with each referral

Previous preterm

$<34$ weeks $65 \%$

$<32$ weeks $13 \%$

$<28$ weeks $3 \%$.

Previous PPROM,

$91 \%$, at gestation

$<28$ weeks $6 \%$

Previous cervical

Incidental finding of

a short cervix $88 \%$.
Investigations ( $n=32$

clinics):

length ultrasound scans

2019):

59\%.

- Vaginal acidity 0\%

- fFN 32\%.

ntions $(n=32$

Primary treatment choice

for asymptomatic

$18 \%$

- IM progesterone 0\%.

$3 \%$

(most commonly

$18 \%$.

Multiple first line

ment options 30\%.

$<15 \mathrm{~mm} \mathrm{3 \%}$

- Centile charts 15\%.

$25 \mathrm{~mm} \mathrm{12 \% .}$

Other cervical length

2019):

activity $45 \%$

- Sick leave 27\%

- Refraining from sexual

Nutrition 27\%.

- No further advice $36 \%$

PPROM premature pre-labour rupture of membranes, LLETZ large loop excision of the transformation zone, LEEP loop electrosurgical excision procedure, fFN fetal fibronectin, IM intramuscular, UK United Kingdom

located in the UK, but clinics in America, Germany, Italy and Australia are also identified. All clinics accepted referrals for women with a previous spontaneous preterm birth, however other referral criteria varied. The majority of clinics saw women with previous mid-trimester loss, previous preterm pre-labour rupture of membranes, 
Table 4 Preterm birth clinic referral criteria

\begin{tabular}{|c|c|}
\hline Referral criteria (non-exclusive) & $\begin{array}{l}\text { Number of clinics } \\
\text { (\%) } n=38^{\text {a }}\end{array}$ \\
\hline Previous spontaneous preterm birth & $38(100)$ \\
\hline$<37$ weeks & $6(16)$ \\
\hline$<35$ weeks & $2(5)$ \\
\hline$<34$ weeks & $20(53)$ \\
\hline$<32$ weeks & $4(11)$ \\
\hline$<28$ weeks & $1(3)$ \\
\hline Other & $1(3)$ \\
\hline No gestational limit reported & $4(11)$ \\
\hline $\begin{array}{l}\text { Previous late miscarriage/mid-trimester } \\
\text { loss }\end{array}$ & $34(89)^{b}$ \\
\hline$\geq 16$ weeks & $2(5)$ \\
\hline No gestational limit reported & $32(84)$ \\
\hline Previous PPROM & $30(79)$ \\
\hline$<37$ weeks & $5(13)$ \\
\hline$<34$ weeks & $17(45)$ \\
\hline$<32$ weeks & $4(11)$ \\
\hline$<28$ weeks & $2(5)$ \\
\hline Other & $1(3)$ \\
\hline No gestational limit reported & $1(3)$ \\
\hline Previous cervical surgery (non-exclusive) & $33(87)$ \\
\hline 1 LLETZ or no number stated & $16(42)$ \\
\hline$\geq 2$ LLETZ & $32(84)$ \\
\hline Knife cone biopsy & $33(87)$ \\
\hline Not further defined & $1(3)$ \\
\hline Other gynaecological procedures (non-exclusive) & $1(3)$ \\
\hline$\geq 3$ Surgical termination of pregnancy & $1(3)$ \\
\hline$\geq 4$ Dilatation and curettage & $1(3)$ \\
\hline Previous cervical cerclage & $1(3)$ \\
\hline Uterine abnormality/malformation & $27(71)$ \\
\hline Short cervix in current pregnancy & $31(82)$ \\
\hline$<25 \mathrm{~mm}$ & $1(3)$ \\
\hline$<3$ rd centile for gestation & $1(3)$ \\
\hline 'Short' cervix not further defined & $29(76)$ \\
\hline Follow up for threatened preterm labour & $4(11)$ \\
\hline Previous stillbirth or neonatal death & $1(3)$ \\
\hline Autoimmune conditions & $1(3)$ \\
\hline Placental risk factors & $1(3)$ \\
\hline Multiple pregnancy & $0(0)$ \\
\hline \multicolumn{2}{|c|}{$\begin{array}{l}\text { UK United Kingdom, PPROM preterm pre-labour rupture of membranes, LLETZ } \\
\text { large loop excision of the transformation zone } \\
\text { a Data not available for one clinic } \\
\text { b Includes } 29 \text { clinics who accepted referrals for recurrent second trimester } \\
\text { miscarriage as referral for a single second trimester miscarriage not reported } \\
\text { in Care } 2019\end{array}$} \\
\hline
\end{tabular}

Table 5 Preterm birth clinic interventions

\begin{tabular}{ll}
\hline $\begin{array}{l}\text { Interventions routinely } \\
\text { offered (non-exclusive) }\end{array}$ & $\begin{array}{l}\text { Number of non-UK } \\
\text { based clinics (\%), } n=6\end{array}$ \\
\hline Cervical cerclage & $6(100)$ \\
Vaginal progesterone & $4(67)$ \\
IM progesterone (17OHP-C) & $2(33)$ \\
Cervical pessary & $1(17)$ \\
& \\
Primary choice of intervention & Number of UK based \\
for women with a sonographic & clinics (\%), $n=33$ \\
short cervix ${ }^{a}$ & \\
Cervical cerclage & $10(30)$ \\
Vaginal progesterone & $6(18)$ \\
Cervical pessary & $1(3)$ \\
Combination therapy ${ }^{b}$ & $6(18)$ \\
Multiple first-line treatment options & $10(30)$
\end{tabular}

UK United Kingdom, IM intramuscular, 17OHP-C 17-alpha

hydroxyprogesterone caproate.

${ }^{a}$ Threshold for a short cervix defined by the individual clinic, further detailed in the text

${ }^{\mathrm{b}}$ Most were combination of cervical cerclage and vaginal progesterone

previous cervical surgery, uterine abnormality or malformation, and a short cervix detected in pregnancy. A minority of clinics also accepted referrals for other indications including history of multiple surgical terminations of pregnancy or dilatation and curettage, as follow up after a diagnosis of threatened preterm labour, and presence of an autoimmune condition. Of interest, no clinic listed previous caesarean section at full

Table 6 Timing of planned first and last preterm birth clinic appointments

\begin{tabular}{ll}
\hline $\begin{array}{l}\text { Gestational age at planned } \\
\text { first clinic appointment }\end{array}$ & Number (\%), $n=35^{a}$ \\
\hline$<12$ weeks & $3(9)$ \\
$12-14$ weeks & $14(40)$ \\
$15-16$ weeks & $16(46)$ \\
$>16$ weeks & $1(3)$ \\
Other ${ }^{b}$ & $1(3)$ \\
Gestational age at planned last & \\
clinic appointment ${ }^{c}$ & Number $(\%), n=26^{d}$ \\
24 weeks & $1(4)$ \\
26 weeks & $1(4)$ \\
28 weeks & $9(35)$ \\
30 weeks & $1(4)$ \\
32 weeks & $2(8)$ \\
34 weeks & $9(35)$ \\
37 weeks or delivery & $3(12)$ \\
\hline
\end{tabular}

UK United Kingdom

${ }^{a}$ Data not available for four clinics

b 10-18 weeks

C If a gestational age range was given, the upper gestation is reported

${ }^{d}$ Data not available for 13 clinics 
dilatation as a referral criteria, despite recent evidence that this is a significant risk factor for spontaneous preterm birth [54, 57].

Transvaginal cervical length scans were used to aid decisions on management in all clinics but the use of additional investigations such as urogenital swabs, urine culture and fetal fibronectin varied. Differences in how interventions were reported limited the ability to synthesise these results, however available evidence shows that a range of interventions are available, with significant variation in the choice of primary management for a sonographic short cervix within the UK, where this data was available. The majority of clinics saw women for their first appointment between 12 and 16 weeks of gestation and cared for them through to the late second or early third trimester. The frequency of preterm birth clinic review was usually directed by clinical findings.

\section{Application of results}

To the best of our knowledge, this is the first systematic review to assess practice in preterm birth clinics globally, and has shown wide variation in most aspects of care. Inconsistencies in care have also been identified as an issue in national surveys of practice in the UK $[23,40]$. This information can be used to support the development and implementation of preterm birth clinic consensus guidelines and national prevention programmes, which are likely to improve consistency and encourage best practice care based on current evidence. The newly introduced 'Reducing Preterm Birth: Guidelines for Commissioners and Providers' [13] is likely to fulfil this role in the UK and may also influence care in other countries; reevaluation of practice following implementation of this guideline will be important to assess its impact. The findings from this review can also be used to assist with service planning as preterm birth clinics continue to be introduced throughout the developed world.

Improving consistency in care will also allow clinics to combine their outcome data in a more meaningful way, enabling high-quality research into the effectiveness of interventions provided in preterm birth clinics, along with comparisons between clinics [5]. The UK Preterm Clinical Network has already developed a bespoke internet-based database that uses an agreed minimal dataset, allowing systematic and standardised collection of clinical data from preterm birth clinics within the network [58]. In 2018, there were seven sites using this database, and an additional 24 sites were registered as Data Collection Centres, four of which are outside of the UK [58]. This collaborative approach to data collection, if combined with a consistent approach to care in preterm birth clinics, has great potential for the future evaluation of existing and new interventions aimed at optimising the care of asymptomatic women at high risk of spontaneous preterm birth.

\section{Limitations}

The main limitation of this review is the potential for incomplete data. Due to the paucity of literature in this area, studies were included that did not specifically assess or report on care in a preterm birth clinic, but reported on another aspect of care in a group of high risk women cared for in a preterm birth clinic. Thus, details about the clinic itself were at times incomplete. We have assumed for the purposes of this review that if a referral criteria, investigation or intervention was not reported, then it was not used. Another limitation is that included data is predominantly from clinics in the UK, so results are likely to favour practice from this region. This is unsurprising as the UK have led the development of modern-day preterm birth clinics and to our knowledge, are the first to recommend the use of preterm birth clinics in national guidelines [13]. Results from the UK also have a lower risk of publication bias due to the availability and inclusion of studies that had taken a cross-sectional survey approach to assessing preterm birth clinic practice [23, 40]. Results from outside of the UK may reflect care from academic preterm birth clinics which are more likely to have published their data or be involved in other research. National or binational surveys of practice in other localities would be helpful and we intend to explore this in Australasia.

We have taken a unique approach to analysis by combining different studies on the same clinic and in our selection of studies suitable for combination and synthesis. This was necessary as the 'population' of interest was the clinic itself, and thus inclusion of all studies would have resulted in over-representation of certain clinics which were described in multiple studies. The assumption that the three clinics reported in other included UK based studies were included within the four anonymous clinics in Care 2019, is a further limitation of this study. However even if not the case, this is unlikely to have changed findings significantly.

\section{Conclusions}

To our knowledge, this is the first systematic review of the practice of preterm birth clinics internationally. Variation in the referral criteria, investigations and interventions, and timing and frequency of review in individual preterm birth clinics was evident. Consistency in care is likely to be improved with the introduction of consensus guidelines and national preterm birth prevention programmes such 
as those recently introduced in the UK. A repeat survey of practice in preterm birth clinics in the UK can be used to assess the impact of new consensus guidelines introduced in the UK, and are also required in other localities.

\section{Supplementary information}

Supplementary information accompanies this paper at https://doi.org/10. 1186/s12884-020-2731-7.

\begin{abstract}
Additional file 1: Table S1. MEDLINE search strategy. Table S2. Methodological quality assessment of included studies based on the Newcastle-Ottawa Scale for cohort and case controlled studies. Table S3. Methodological quality assessment of included studies based on the modified Newcastle-Ottawa Scale for cross-sectional studies. Table S4. Methodological quality assessment of included studies based on the Cochrane Risk of Bias Tool for randomized controlled trials. Table S5. Methodological quality assessment of included qualitative studies based on the Critical Appraisal Skills Programme Checklist for qualitative research.
\end{abstract}

\section{Abbreviations}

CASP: Critical Appraisal Skills Programme; MeSH: Medical Subject Headings; NICE: National Institute for Health and Care Excellence; PRESS: Peer Review of Electronic Search Strategies; PRISMA: Preferred Reporting Items for Systematic Reviews and Meta-Analyses; PROSPERO: International Prospective Register of Systematic Reviews; UK: United Kingdom

\section{Acknowledgements}

The authors would like to acknowledge Ms. Anne Wilson and Dr. Sandy Lin, Research Services Advisors at The University of Auckland, for their assistance in developing the search strategy and for support with the database searches.

\section{Authors' contributions}

LD was lead investigator in this review, she drafted the protocol, developed the search strategy, ran the search, assessed studies for eligibility and inclusion, performed data extraction, quality assessments and data analysis and wrote the first draft of the manuscript. KG conceived the idea, assisted with protocol development and contributed to revision of the manuscript. $\mathrm{VJ}$ assisted with protocol development, provided methodological advice and support, and contributed to revision of the manuscript. JW was the supervising investigator, he assisted with protocol development, assessed studies for eligibility and inclusion, checked extracted data, performed quality assessments, assisted with data analysis and contributed to revision of the manuscript. All authors approved the final version of the manuscript prior to submission.

\section{Authors' information}

LD is a Clinical Research Fellow and Doctor of Medicine candidate at the Liggins Institute at the University of Auckland. She is also an Advanced Trainee in Obstetrics and Gynaecology and a Clinical Fellow in the Preterm Birth Clinic at National Women's Health, Auckland City Hospital. KG is an Associate Professor of Maternal and Perinatal Health and the Hugo Charitable Trust Research Fellow at the Liggins Institute at the University of Auckland. She is also a Subspecialist in Maternal and Fetal Medicine and is the Clinical Lead of the Preterm Birth Service at National Women's Health, Auckland City. VJ is a Senior Research Fellow in the Department of Obstetrics and Gynaecology at the University of Auckland and a Fellow of the New Zealand Cochrane Group. JW is an Associate Professor in the Department of Obstetrics and Gynaecology at the University of Auckland. He is also the Clinical Director of Tertiary Obstetric Services and a specialist in the Preterm Birth Clinic at National Women's Health, Auckland City Hospital.

\section{Funding}

The Auckland Medical Research Foundation, Mercia Barnes Trust and Hugo Charitable Trust have provided partial salary support for LD. KG is supported by the Hugo Charitable Trust.

\section{Availability of data and materials}

All data generated or analysed during this study are included in this published article and its supplementary information files.

Ethics approval and consent to participate

Not applicable.

\section{Consent for publication}

Not applicable.

\section{Competing interests}

The authors declare that they have no competing interests.

\section{Author details}

'Liggins Institute, The University of Auckland, Private Bag 92019, Victoria Street West, Auckland 1142, New Zealand. ${ }^{2}$ National Women's Health, Auckland City Hospital, Auckland, New Zealand. ${ }^{3}$ Department of Obstetrics \& Gynaecology, The University of Auckland, Auckland, New Zealand. ${ }^{4}$ Cochrane New Zealand, Auckland, New Zealand.

Received: 2 December 2019 Accepted: 9 January 2020

Published online: 29 January 2020

\section{References}

1. March of Dimes, Partnership for Maternal Newborn and Child Health, Save the Children, World Health Organisation. Born Too Soon: The Global Action Report on Preterm Birth [Internet]Geneva: World Health Organization; 2012 [Available from: https://www.marchofdimes.org/materials/born-too-soonthe-global-action-report-on-preterm-.pdf

2. Goldenberg RL, Culhane JF, lams JD, Romero R. Epidemiology and causes of preterm birth. Lancet. 2008;371(9606):75-84.

3. Hamilton SA, Mullan C. Management of preterm labour. Obstet Gynaecol Reprod Med. 2016;26(1):12-9.

4. Haram K, Mortensen JHS, Morrison JC. Tocolysis for acute preterm labor: does anything work. J Matern Fetal Neonatal Med. 2015;28(4):371-8.

5. Vernet $G$, Watson $H$, Ridout A, Shennan A. The role of PTB clinics: a review of the screening methods, interventions and evidence for preterm birth surveillance clinics for high-risk asymptomatic women. Women Health Bull. 2017;4(4)::12667.

6. Crane JMG, Hutchens D. Transvaginal sonographic measurement of cervical length to predict preterm birth in asymptomatic women at increased risk: a systematic review. Ultrasound Obstet Gynecol. 2008;31(5):579-87.

7. Abbott DS, Hezelgrave NL, Seed PT, Norman JE, David AL, Bennett PR, et al. Quantitative fetal fibronectin to predict preterm birth in asymptomatic women at high risk. Obstet Gynecol. 2015;125(5):1168-76.

8. Conde-Agudelo A, Romero R, Nicolaides K, Chaiworapongsa T, O'Brien JM, Cetingoz $\mathrm{E}$, et al. Vaginal progesterone vs cervical cerclage for the prevention of preterm birth in women with a sonographic short cervix, previous preterm birth, and singleton gestation: a systematic review and indirect comparison metaanalysis. Am J Obstet Gynecol. 2013;208(1):42 e1e18.

9. Jorgensen A, Alfirevic Z, Smith CT, Williamson P. Systematic review: cervical stitch (cerclage) for preventing pregnancy loss: individual patient data meta-analysis. BJOG Int J Obstet Gynaecol. 2007;114(12):1460-76.

10. Romero R, Nicolaides K, Conde-Agudelo A, Tabor A, O'Brien JM, Cetingoz E, et al. Vaginal progesterone in women with an asymptomatic sonographic short cervix in the midtrimester decreases preterm delivery and neonatal morbidity: a systematic review and metaanalysis of individual patient data. Am J Obstet Gynecol. 2012;206(2):124 e1-e19.

11. Whitworth M, Quenby S, Cockerill RO, Dowswell T. Specialised antenatal clinics for women with a pregnancy at high risk of preterm birth (excluding multiple pregnancy) to improve maternal and infant outcomes. Cochrane Database Syst Rev. 2011;9.

12. Malouf R, Redshaw M. Specialist antenatal clinics for women at high risk of preterm birth: a systematic review of qualitative and quantitative research. BMC Pregnancy Childbirth. 2017;17(1):51.

13. UK Preterm Clinical Network. Reducing Preterm birth: guidelines for commissioners and providers [internet]. United Kingdom: UK Preterm Clinical Network; 2019. Available from: https://www.tommys.org/sites/ default/files/Preterm\%20birth\%20guidelines.pdf 
14. National Institute for Health and Care Excellence. Preterm labour and birth [internet]. United Kingdom: National Institute for Health and Care Excellence; 2015. Available from: https://www.nice.org.uk/guidance/ng25/ resources/preterm-labour-and-birth-pdf-1837333576645.

15. Moher D, Liberati A, Tetzlaff J, Altman DG. Preferred reporting items for systematic reviews and meta-analyses: The PRISMA statement. PLoS Med. 2009;6(7):e1000097.

16. McGowan J, Sampson M, Salzwedel DM, Cogo E, Foerster V, Lefebvre C. PRESS peer review of electronic search strategies: 2015 guideline statement. J Clin Epidemiol. 2016;75:40-6.

17. Clarivate Analytics. EndNote X8. Philadelphia: Clarivate Analytics; 2016.

18. Veritas Health Innovation. Covidence systematic review software. Melbourne: Veritas Health Innovation; 2019.

19. Cochrane Effective Practice and Organisation of Care (EPOC). Suggested risk of bias criteria for EPOC reviews 2017. Available from: https://epoc.cochrane. org/sites/epoc.cochrane.org/files/public/uploads/Resources-for-authors2017/ suggested_risk_of_bias_criteria_for_epoc_reviews.pdf.

20. Wells GA, Shea B, O'Connell D, Peterson J, Welch V, Losos M, et al The NewcastleOttawa scale (NOS) for assessing the quality of non-randomised studies in metaanalyses. Ottawa: Ottawa Health Research Institute; 2019. Available from: http:// www.ohri.ca/programs/clinical_epidemiology/nosgen.pdf.

21. Herzog R, Álvarez-Pasquin MJ, Díaz C, Del Barrio JL, Estrada JM, Gil Á. Are healthcare workers' intentions to vaccinate related to their knowledge, beliefs and attitudes? A systematic review. BMC Public Health. 2013;13(1):154.

22. Critical Appraisal Skills Programme. CASP checklist: 10 questions to help you make sense of a qualitative research. Oxford: Critical Appraisal Skills Programme; 2018 [June 2019]. Available from: https://casp-uk.net/wpcontent/uploads/2018/03/CASP-Qualitative-Checklist-2018_fillable_form.pdf.

23. Care A, Ingleby L, Alfirevic Z, Sharp A. The influence of the introduction of national guidelines on preterm birth prevention practice: UK experience. BJOG Int J Obstet Gynaecol. 2019;126(6):763-9.

24. Vousden N, Hezelgrave N, Carter J, Seed PT, Shennan AH. Prior ultrasoundindicated cerclage: how should we manage the next pregnancy? Eur J Obstet Gynecol Reprod Biol. 2015;188:129-32.

25. Kuhrt K, Hezelgrave N, Foster C, Seed PT, Shennan AH. Development and validation of a tool incorporating quantitative fetal fibronectin to predict spontaneous preterm birth in symptomatic women. Ultrasound Obstet Gynecol. 2016;47(2):210-6.

26. Cohen A, Kindinger $L$, Clifford $K$, Bennett $P$, Teoh $T$. Who is most at risk: a preterm surveillance clinic audit. BJOG Int J Obstet Gynaecol. 2014;121:16.

27. Bolt LA, Chandiramani M, De Greeff A, Seed PT, Kurtzman J, Shennan AH. The value of combined cervical length measurement and fetal fibronectin testing to predict spontaneous preterm birth in asymptomatic high-risk women. J Matern Fetal Neonatal Med. 2011;24(7):928-32.

28. Ivandic J, Care A, Goodfellow L, Poljak B, Sharp A, Roberts D, et al. Cervical pessary for short cervix in high risk pregnant women: 5 years experience in a single centre. J Matern Fetal Neonatal Med. 2018:1-7.

29. Karkhanis P, Patni S, Gargeswari S. Performance of the preterm prevention clinic at Heart of England NHS Trust. Int J Gynecol Obstet. 2012;119(S3):S386.

30. Yulia A, Thomas S, Singh N, Johnson MR, Wales NM, Terzidou V. Pregnancy outcome following the indication of cerclage. BJOG Int J Obstet Gynaecol. 2015;122:226-7.

31. Kindinger L, TG T. Preterm delivery - who is most at risk? An audit of a preterm surveillance clinic. BJOG Int J Obstet Gynaecol. 2013;120(3):50.

32. Burul G, James C, Forya F, Casagrandi D, Tetteh A, Al-Fahdi B, et al. Does specialist antenatal care for women at risk of preterm birth affect patient selection, rate and outcomes of cervical cerclage? Arch Dis Child Fetal Neonatal Ed. 2014;99(Suppl 1):A154-A.

33. O'Brien ET, Quenby S, Lavender T. Women's views of high risk pregnancy under threat of preterm birth. Sex Reprod Healthc. 2010;1(3):79-84.

34. Kindinger LM, Kyrgiou M, Maclntyre DA, Cacciatore S, Yulia A, Cook J, et al. Preterm birth prevention post-conization: a model of cervical length screening with targeted cerclage. PLoS One. 2016;11(11):e0163793.

35. Watson HA, Carter J, Seed PT, Tribe RM, Shennan AH. The QUiPP app: a safe alternative to a treat-all strategy for threatened preterm labor. Ultrasound Obstet Gynecol. 2017:50(3):342-6.

36. Grant N, Raouf S. A prospective population-based study to investigate the effectiveness of interventions to prevent preterm birth. BJOG Int J Obstet Gynaecol Conf. 2016;123:96

37. Bolt LA, Chandiramani M, De Greeff A, Seed P, Shennan AH. Combining cervical length measurement and fetal fibronectin testing to predict spontaneous preterm birth in asymptomatic high risk women. BJOG Int J Obstet Gynaecol. 2010;117(5):624.

38. Khambay H, Bolt L, Chandiramani M, De Greeff A, Shennan AH. The use of phosphorylated insulin-like growth factor binding protein-1, the actim partus test to predict preterm birth in asymptomatic high-risk women. J Matern Fetal Neonatal Med. 2010;1:109-10.

39. Porter F, Henry E, Esplin S, Manuck T, Varner M, Gibson J. Effect of 'preterm birth prevention clinic' on pregnancy outcomes among women at high risk for recurrent spontaneous preterm birth. Am J Obstet Gynecol. 2011;204(1 SUPPL):S29-30.

40. Sharp A, Alfirevic Z. Provision and practice of specialist preterm labour clinics: a UK survey of practice. BJOG Int J Obstet Gynaecol. 2014;121(4):417-21.

41. Khambay H, Bolt LA, Chandiramani M, De Greeff A, Filmer JE, Shennan AH. The Actim Partus test to predict pre-term birth in asymptomatic high-risk women. J Obstet Gynaecol. 2012;32(2):132-4.

42. Duhig KE, Chandiramani M, Seed PT, Briley AL, Kenyon AP, Shennan AH. Fetal fibronectin as a predictor of spontaneous preterm labour in asymptomatic women with a cervical cerclage. BJOG Int J Obstet Gynaecol. 2009;116(6):799-803.

43. Min J, Watson HA, Hezelgrave NL, Seed PT, Shennan AH. Ability of a preterm surveillance clinic to triage risk of preterm birth: a prospective cohort study. Ultrasound Obstet Gynecol. 2016;48(1):38-42.

44. Smout EM, Seed PT, Shennan AH. Fetal fibronectin as a predictor of PTB in primiparous women with cervical surgery. J Matern Fetal Neonatal Med. 2010;(1): 306-7.

45. Alfirevic Z, Owen J, Carreras Moratonas E, Sharp AN, Szychowski JM, Goya M. Vaginal progesterone, cerclage or cervical pessary for preventing preterm birth in asymptomatic singleton pregnant women with a history of preterm birth and a sonographic short cervix. Ultrasound Obstet Gynecol. 2013;41(2):146-51.

46. Care AG, Sharp AN, Lane S, Roberts D, Watkins L, Alfirevic Z. Predicting preterm birth in women with previous preterm birth and cervical length $>=$ 25 mm. Ultrasound Obstet Gynecol. 2014;43(6):681-6.

47. Care A, Sharp A, Alfirevic Z. Arabin pessary to prevent spontaneous preterm birth: experience of a specialist preterm labour clinic. Arch Dis Child Fetal Neonatal Ed. 2014,99.

48. Raouf S, Ghazal F, Sunanda G, Patni S. Has 'Preterm Prevention Clinic' made a difference? Int J Gynecol Obstet. 2009;2:S425.

49. Turitz AL, Bastek JA, Purisch SE, Elovitz MA, Levine LD. Patient characteristics associated with 17-alpha hydroxyprogesterone caproate use among a highrisk cohort. Am J Obstet Gynecol. 2016;214(4):536 e1-e5.

50. Manuck TA, Henry E, Gibson J, Varner MW, Porter TF, Jackson GM, et al. Pregnancy outcomes in a recurrent preterm birth prevention clinic. Am J Obstet Gynecol. 2011;204(4):320 e1-e6.

51. Hughes K, Sim S, Roman A, Michalak K, Kane S, Sheehan P. Outcomes and predictive tests from a dedicated specialist clinic for women at high risk of preterm labour: a ten year audit. Aust N Z J Obstet Gynaecol. 2017;57(4):405-11.

52. Stricker N, Timmesfeld N, Kyvernitakis I, Goerges J, Arabin B. Vaginal progesterone combined with cervical pessary: a chance for pregnancies at risk for preterm birth? Am J Obstet Gynecol. 2016;214(6):739 e1-e10.

53. Danti L, Zonca M, Barbetti L, Lojacono A, Marini S, Cappello N, et al. Prophylactic oral nifedipine to reduce preterm delivery: a randomized controlled trial in women at high risk. Acta Obstet Gynecol Scand. 2014;93(8):802-8.

54. Watson HA, Carter J, David AL, Seed PT, Shennan AH. Full dilation cesarean section: a risk factor for recurrent second-trimester loss and preterm birth. Acta Obstet Gynecol Scand. 2017;96(9):1100-5.

55. Kuhrt K, Smout E, Hezelgrave N, Seed PT, Carter J, Shennan AH. Development and validation of a tool incorporating cervical length and quantitative fetal fibronectin to predict spontaneous preterm birth in asymptomatic high-risk women. Ultrasound Obstet Gynecol. 2016;47(1):104-9.

56. Newnham JP, White SW, Meharry S, Lee H-S, Pedretti MK, Arrese CA, et al. Reducing preterm birth by a statewide multifaceted program: an implementation study. Am J Obstet Gynecol. 2017;216(5):434-42.

57. Wood SL, Tang S, Crawford S. Cesarean delivery in the second stage of labor and the risk of subsequent premature birth. Am J Obstet Gynecol. 2017;217(1):63 e1-e10.

58. Carter J, Tribe RM, Sandall J, Shennan AH, Alfirevic Z, Adamson C, et al. The Preterm Clinical Network (PCN) database: a web-based systematic method of collecting data on the care of women at risk of preterm birth. BMC Pregnancy Childbirth. 2018;18(1):335.

\section{Publisher's Note}

Springer Nature remains neutral with regard to jurisdictional claims in published maps and institutional affiliations. 